\title{
Prospective six year follow up of patients withdrawn from a randomised study comparing parenteral gold salt and methotrexate
}

\author{
Oliver Sander, Gertraud Herborn, Elisabeth Bock, Rolf Rau
}

\begin{abstract}
Objective-To confirm the impression of a better outcome of patients withdrawn from parenteral gold salt therapy compared with those withdrawn from methotrexate.

Methods-Patients with early, active, and erosive RA were randomised for a double blind trial to receive either weekly $15 \mathrm{mg}$ intramuscular methotrexate or $50 \mathrm{mg}$ goldsodiumthiomalate. If the drug had to be withdrawn because of side effects treatment was continued with the other drug in still active disease. Patients with insufficient response were treated with a combination of both drugs. All patients were followed up by an extended clinical and radiographic evaluation.

Results-64 patients each were allocated to methotrexate and gold treatment. After 72 months a complete record was available for $88 \%$ of patients. Within the first 36 months 38 patients withdrew from gold treatment ( $95 \%$ because of side effects) and 23 patients withdrew from methotrexate $(57 \%$ because of side effects). A significant $40 \%$ to $70 \%$ improvement of all parameters (erythrocyte sedimentation rate, $C$ reactive protein, swollen and tender joints, radiological progression) compared with baseline was observed in patients completing their randomised treatment with gold or methotrexate. The same improvement over three years was seen in patients who withdrew from gold treatment, while patients withdrawing from methotrexate experienced a deterioration of their disease.

Conclusion-Withdrawals represent the majority of patients in long term drug trials. Patients with early RA stopping gold because of side effects show almost the same sustained improvement as patients continuing gold or methotrexate. Patients withdrawn from methotrexate experience a reactivation of their disease.

(Ann Rheum Dis 1999;58:281-287)
\end{abstract}

Department of

Rheumatology,

Ratingen, Germany

Correspondence to:

Dr O Sander,

Rheumatologie, Ev

Fachkrankenhaus Ratingen,

Rosenstr 2, 40882 Ratingen,

Germany.

Accepted for publication

25 January 1999

Methotrexate (MTX) and parenteral gold have been shown to improve clinical and laboratory parameters of disease activity and to reduce radiological progression thereby improving the outcome of rheumatoid arthritis. Randomised clinical trials could not demonstrate any difference in efficacy between patients treated with methotrexate or with parenteral gold. ${ }^{1-5}$ MTX shows a rapid onset of action and has been shown to be efficacious also in the long term treatment..$^{6-11}$ Usually, it is well tolerated, has a low drop out rate and therefore can be continued for a longer period of time than any other disease modifying antiarthritic drug (DMARD). ${ }^{12-16}$ In comparison with methotrexate, parenteral gold treatment is complicated by higher toxicity related drop out rates. ${ }^{17-23}$

Several authors have reported a marked improvement or even longlasting remissions in patients with gold related toxicity. ${ }^{23}$ This clinical observation has never been confirmed by prospective clinical trials. For that reason we followed up over several years patients from a double blind study who discontinued a randomised treatment with parenteral gold salt (GSTM) or MTX.

\section{Methods}

PATIENTS

The study design has been outlined previously. ${ }^{2}$ It was conducted as a double blind randomised parallel group trial comparing the efficacy of MTX and GSTM in patients with definite rheumatoid arthritis according to the American College of Rheumatology criteria. ${ }^{24} \mathrm{At}$ study entry all patients had active disease defined as the presence of three of the following criteria: (1) erythrocyte sedimentation rate $(\mathrm{ESR})>20 \mathrm{~mm} 1 \mathrm{st} \mathrm{h}$ in men and $>30 \mathrm{~mm} 1 \mathrm{st}$ $\mathrm{h}$ in women; (2) morning stiffness $>1$ hour; (3) $>6$ swollen joints; $(4)>9$ tender joints. Additionally, patients had to have erosive disease, defined as at least a $2 \mathrm{~mm}$ discontinuation of cortical bone at one site.

Patients were excluded if they had advanced disease with (1) deformities (for example, subluxation, ulnar deviation) or (2) serious radiographic changes according to Larsen stage III-V in any joint ${ }^{25}$; patients were excluded if they had been treated with MTX or GSTM previously, if they had been treated with any other DMARD during the past three months, if they had had intra-articular corticosteroid injections within the previous four weeks or had conditions that preclude treatment with MTX or parenteral gold. All patients signed informed written consent to participate in the study.

\section{TREATMENT}

Patients were randomly assigned to weekly injections of $50 \mathrm{mg}$ GSTM or $15 \mathrm{mg}$ MTX in a double blind fashion during the first year. After unblinding at month 12 treatment was continued with the same dose in MTX treated 
Table 1 Baseline patient characteristics (mean values (SD))

\begin{tabular}{|c|c|c|c|}
\hline & Completer & $M T X$ withdrawals & GSTM withdrawals \\
\hline Number & 67 & 23 & 38 \\
\hline Female & $70 \%$ & $61 \%$ & $71 \%$ \\
\hline Rheumatoid factor positive & $55 \%$ & $65 \%$ & $63 \%$ \\
\hline \multirow{2}{*}{\multicolumn{4}{|c|}{$\begin{array}{l}\text { Shared epitope positive }\left({ }^{\star} 0101,{ }^{\star} 0401,{ }^{\star} 0404,{ }^{\star} 0408,{ }^{\star} 1001\right. \\
\left.\text { or }{ }^{\star} 1402\right)\end{array}$}} \\
\hline & $79 \%$ & $39 \%$ & $50 \%$ \\
\hline Taking prednisone $(<10 \mathrm{mg} /$ day, $\%)$ & $24 \%$ & $26 \%$ & $26 \%$ \\
\hline Prednisone dose (when given, $\mathrm{mg}$ /day) & $6.10(2.02)$ & $5.51(2.19)$ & $5.90(1.56)$ \\
\hline Disease duration (months) & $16.5(16.2)$ & $16.3(14.2)$ & $16.6(18.3)$ \\
\hline Swollen joint count $(0-38)$ & $15.2(6.8)$ & $17.5(6.6)$ & $14.1(6.6)$ \\
\hline Tender joint count $(0-38)$ & $16.6(6.9)$ & $19.8(9.1)$ & $19.3(6.2)$ \\
\hline Erythrocyte sedimentation ( $\mathrm{mm} 1 \mathrm{st} \mathrm{h}$ ) & $37.2(22.7)$ & $36.5(22.9)$ & $38.9(23.4)$ \\
\hline $\mathrm{C}$ reactive protein $(\mathrm{mg} / \mathrm{l})$ & $41.7(40.1)$ & $45.8(39.2)$ & $45.3(40.2)$ \\
\hline \multicolumn{4}{|l|}{ Pretreatment radiological progression (increase in Ratingen } \\
\hline Disease activity score & $5.44(0.75)$ & $5.59(0.73)$ & $5.55(0.84)$ \\
\hline
\end{tabular}

patients while the GSTM dose was reduced to $50 \mathrm{mg}$ every second week. Patients who showed no improvement or a deterioration according to the predefined criteria (see below) after 12 months continued treatment with the combination of $50 \mathrm{mg}$ GSTM and $15 \mathrm{mg} \mathrm{MTX/}$ week.

In case of intolerable side effects the study medication was paused for two weeks. If toxicity remained or reappeared, the corresponding study medication was stopped permanently. Withdrawn patients who showed a remission or at least a "marked improvement" were followed up without treatment until the disease flared up again. Patients with active disease were switched to the counter study medication.

Concomitant treatment with NSAIDs and prednisone in a daily dose $<10 \mathrm{mg}$ was allowed, the doses were recorded.

CLINICAL AND LABORATORY EVALUATIONS Clinical evaluations were done at baseline and after months $1,3,6,9,12,18,24,30,36,48$, 60 , and 72 by the same physician $(\mathrm{GH})$. All patients who completed the trial on their original study medication and those who discontinued the randomised treatment were examined according to study design.

Safety monitoring included a physical examination and control of laboratory parameters. All side effects were recorded according to the WHO classification. ${ }^{26}$

Efficacy assessments included the number of tender and swollen joints (38 joints were counted: metacarpophalangeal (MCP) joints $\mathrm{I}-\mathrm{V}$, proximal interphalangeal (PIP) joints II-V, interphalangeal (IP) joints of the thumbs, wrists, elbows, shoulder joints, knee joints, ankle joints, metatarsophalangeal (MTP) joints II-V), $C$ reactive protein (CRP), and ESR.

Response to treatment was defined as follows: (1) clinical remission: no swollen and < 2 tender joints; ESR $<20 \mathrm{~mm} 1$ st $\mathrm{h}$ in men, $<$ $30 \mathrm{~mm} 1 \mathrm{st} \mathrm{h}$ in women and no systemic or intra-articular corticosteroids during the past four weeks; (2) marked improvement: swollen joint count $<50 \%$ of baseline and daily dose of prednisone $<5 \mathrm{mg}$ during the past four weeks; (3) improvement: swollen joint count at $51-80 \%$ of baseline and daily dose of prednisone $\leqslant 7.5 \mathrm{mg}$; (4) no improvement: swollen joint count at $81-120 \%$ of baseline; (5) deterioration: swollen joint count of more than $120 \%$ of baseline values.

The response rates according to the European League Against Rheumatism (EULAR) response criteria based on the disease activity score (DAS) ${ }^{27}$ were calculated retrospectively.

Standardised radiographs of hands and forefeet were taken at baseline and after $6,12,24$, $36,48,60$, and 72 months. All radiographs were read by one observer $(\mathrm{GH})$ blinded to patient identity and treatment but knowing the sequence of films. The radiographic destruction was measured semiquantitatively by a validated new scoring method ${ }^{28}$ in 38 joints, respectively regions (IP joints of both thumbs, the PIP joints II-V, MCP joints I-V, Os naviculare, Os lunatum, radius, ulna, IP joints of both big toes, MTP joints II-V). Grading entails a semiquantitative evaluation of the destruction of the joint surface: grade $1=$ definite erosion with $<20 \%$ destruction of the joint surface, grade $2=21-40 \%$, grade $3=41-60 \%$, grade 4 $=61-80 \%$, grade $5 \geqslant 80 \%$ destruction of the joint surface; total scores ranged from 0-190.

The radiological progression was calculated as the average monthly increase in the total score per patient. The pretreatment radiological progression was estimated by dividing the baseline score through the disease duration in months.

\section{STATISTICAL ANALYSIS}

Three cohorts were analysed: patients continuing randomised MTX or GSTM treatment for at least 36 months (completers) and patients discontinuing during the first 36 months (MTX withdrawals, GSTM withdrawals). MTX and GSTM completers were analysed as one group to increase statistical power of the tests, as there were no significant differences between both cohorts. ${ }^{2-4}$ Continuous variables were tested with a two tailed $t$ test after confirming standardised distribution. Qualitative variables were tested according to $\chi^{2}$ statistics.

\section{Results}

The study was started as a two centre study and included 174 patients. ${ }^{2-4}$ The prospective six year follow up of all patients was only performed in one centre: 128 patients were enrolled between December 1986 and January 1990. After randomisation 64 patients each 

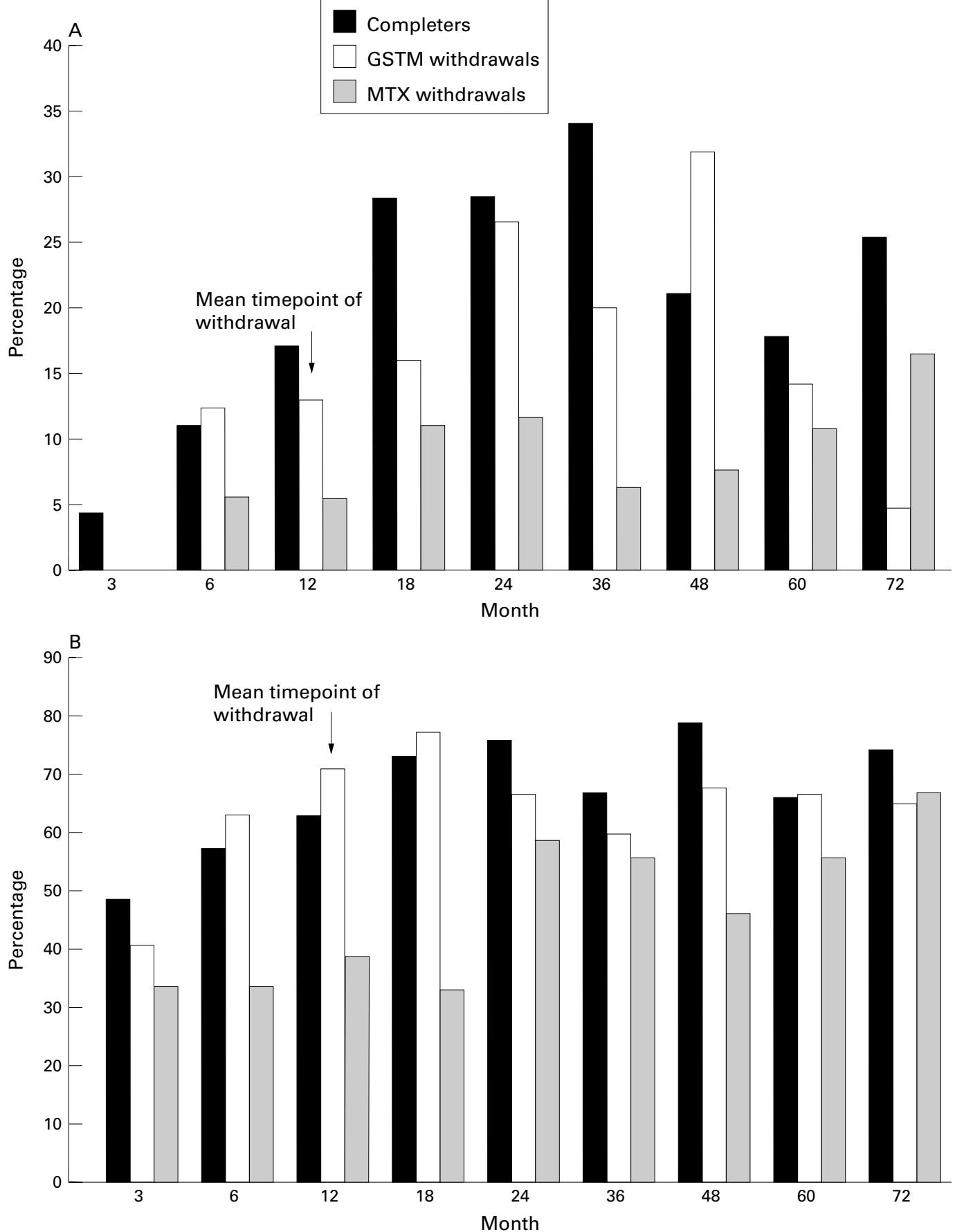

Figure 1 (A) Proportion of patients with good response according to the EULAR criteria in completers and withdrawals (GSTM and MTX). (B) Proportion of patients with moderate response according to the EULAR criteria in completers and withdrawals (GSTM and MTX).

were allocated to the MTX and GSTM treatment group, respectively. Baseline demographic data showed no significant differences between the patients in both treatment groups. There were also no significant differences between the completers, the MTX and the GSTM withdrawals (table 1). After 72 months a complete record of safety and clinical efficacy data as well as radiological progression was available for 113 patients representing $88 \%$ of the randomised population. Seven patients were deceased and eight patients were lost to follow up. During the first 36 months the majority of patients randomised for GSTM (38 of $64,59 \%$ ) stopped treatment. The mean time to discontinuation was 11.3 months (range 1-31). During the same period MTX treat- ment was discontinued in 23 patients (36\%) after a mean of 11.9 months (1-24). GSTM was discontinued significantly $(\mathrm{p}<0.05)$ more often because of toxicity than MTX $(95 \% v$ $57 \%$ ), whereas lack of efficacy was observed more often in the MTX group (43\% v 5\%).

Twelve GSTM withdrawals continued treatment with MTX and 23 were followed up without DMARD treatment because they had reached remission or at least a predefined state of "marked improvement". One patient died and two were lost to follow up. Eight of 10 MTX withdrawals related to a lack in efficacy were treated with the combination therapy according to the study design and two were lost to follow up. Eleven MTX withdrawals related to toxicity still had active disease with a flare up 


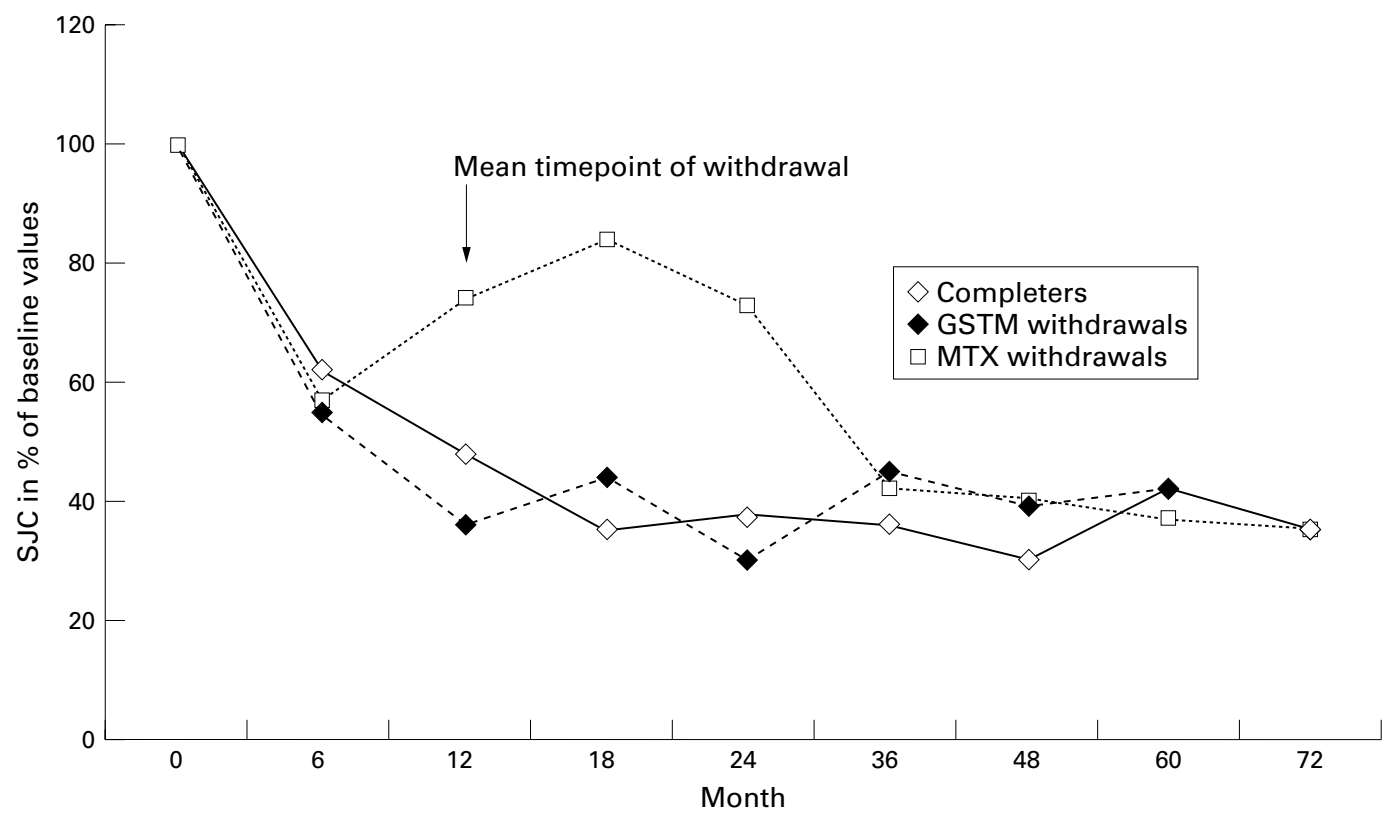

Figure 2 Swollen joint count in completers and withdrawals (GSTM and MTX). Response to treatment shown as percentage of baseline.

after discontinuation. All were consequently treated with GSTM but in three patients a lower dose of MTX was reintroduced in combination with GSTM because of an extended flare up, and two patients died.

The side effects in GSTM treated patients leading to discontinuation were exanthema $(n=22)$, exanthema and stomatitis $(n=7)$, stomatitis $(n=3)$, alopecia $(n=1)$, nausea $(n=1)$, and neuropathy $(n=1)$. Similar side effects also occurred in GSTM completersexanthema $(n=13)$, exanthema and stomatitis $(n=5)$, stomatitis $(n=2)$, and alopecia $(n=1)$ but did not lead to discontinuation of the drug. Also in MTX treated patients exanthema $(n=5)$ and stomatitis $(n=6)$ were not uncommon.

Table 2 Study status at month 36 (mean values (range))

\begin{tabular}{lll}
\hline & MTX & GSTM \\
\hline Randomised (n) & 64 & 64 \\
Completers (\%) & 64 & 41 \\
Withdrawals (\%) & 36 & 59 \\
Time to withdrawal (months) & $11.9(1-24)$ & $11.3(1-31)$ \\
Withdrawal because of toxicity (\%) & 57 & 95 \\
Withdrawal because of lack of efficacy (\%) & 43 & 5 \\
Clinical remission at any time (completers) (\%) & 61 & 54 \\
Time to remission (months) (mithionals) (\%) & $13.7(1-36)$ & $13.0(3-30)$ \\
Clinical remission at any time (withdrawa) & 26 & 58 \\
Time to remission (months) & $16.2(6-36)$ & $9.4(1-30)$ \\
\hline
\end{tabular}

Table 3 Outcome parameters shown as percentage of baseline

\begin{tabular}{|c|c|c|c|c|c|c|c|c|c|c|}
\hline Month & & 0 & 6 & 12 & 18 & 24 & 36 & 48 & 60 & 72 \\
\hline \multirow{4}{*}{ SJC } & completers & 100 & 62 & 48 & 35 & 38 & 36 & 30 & 42 & 35 \\
\hline & GSTM withdrawal & 100 & 55 & $36 \dagger$ & $44 \dagger$ & $30 \dagger$ & 45 & 39 & 42 & 35 \\
\hline & MTX withdrawal & 100 & 57 & $74^{\star} \dagger$ & $84^{\star} \dagger$ & $73^{\star} \dagger$ & 42 & 40 & 37 & 35 \\
\hline & completers & 100 & 63 & 52 & 43 & 42 & 45 & 35 & 48 & 50 \\
\hline \multirow[t]{3}{*}{ TJC } & GSTM withdrawal & 100 & 70 & 41 & 41 & 30 & 40 & 42 & 51 & 32 \\
\hline & MTX withdrawal & 100 & 70 & 66 & $65^{\star}$ & 53 & 56 & 48 & 58 & 37 \\
\hline & completers & 100 & 57 & 49 & 49 & 49 & 46 & 45 & 54 & 52 \\
\hline \multirow[t]{3}{*}{ ESR } & GSTM withdrawal & 100 & 61 & 52 & $41 \dagger$ & 51 & 56 & 53 & 56 & $83^{\star}$ \\
\hline & MTX withdrawal & 100 & 75 & $91^{\star}$ & $83^{\star} \dagger$ & 71 & 56 & 62 & 78 & 71 \\
\hline & completers & 100 & 56 & 48 & 44 & 35 & 32 & 27 & 32 & 27 \\
\hline \multirow[t]{2}{*}{ CRP } & GSTM withdrawal & 100 & 55 & $47 \dagger$ & $44 \dagger$ & $39 \dagger$ & 42 & 40 & 31 & 39 \\
\hline & MTX withdrawal & 100 & $88^{\star}$ & $148^{\star} \dagger$ & $133^{\star} \dagger$ & $86^{\star} \dagger$ & 34 & 35 & 59 & 40 \\
\hline
\end{tabular}

( ${ }^{\star}$ Significant difference compared with completers, †significant difference between GSTM and MTX withdrawals, $t$ test, $\mathrm{p}<0.05$ ).
The predominant reasons for withdrawal of MTX were lack of efficacy $(n=10)$, nausea $(n=7)$, nausea and arthralgia $(n=2)$, and respiratory tract infection $(n=2)$. All drug related side effects were mild or moderate according to the WHO criteria and resolved spontaneously within the observation period. Three patients died because of pre-existing cardiovascular disease (two myocardial infarctions, one cerebral insult).

The most favourable outcome, clinical remission, according to the predefined criteria, was reached by $58 \%$ of the completers. Sixty six per cent of the GSTM withdrawals but only $26 \%$ of MTX withdrawals fulfilled the criteria of clinical remission. The mean time to clinical remission in GSTM withdrawals was 9.4 months (range 1-30), approximately two months before withdrawal. The improvement was transient in some patients but nine GSTM withdrawals $(24 \%)$ were still in remission after 36 months and 12 patients (32\%) showed marked improvement. In contrast with gold withdrawals the mean time to remission within the MTX withdrawals was 16.2 months (6-36)-on average 4.3 months after withdrawal (table 2).

The data were confirmed by the EULAR response criteria, retrospectively. The proportions of patients with a good response (DAS < 2.4) and moderate response (DAS decrease $>$ 1.2) are shown in figure $1 \mathrm{~A}$ and $\mathrm{B}$. Completers and GSTM withdrawals show the same favourable results being superior to MTX withdrawals.

In GSTM withdrawals swollen and tender joint counts declined to an average of $30 \%$ of baseline values at month 24 (12 months after withdrawal) compared with $40 \%$ in completers. In contrast, MTX withdrawals improved only to $70 \%$ of baseline values in the swollen joint count (SJC) and 53\% in the tender joint count (TJC). Later in the course of the disease 


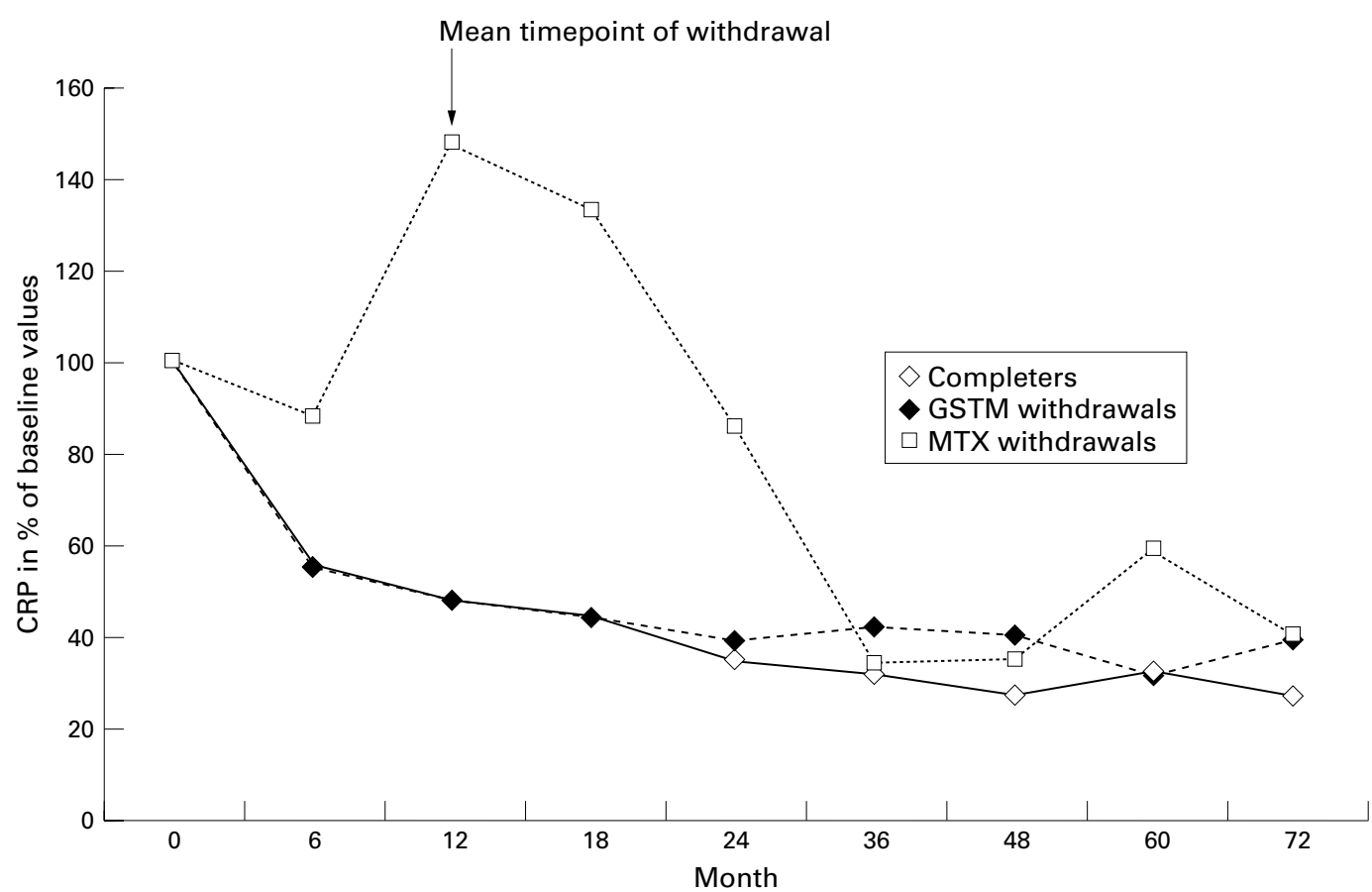

Figure 3 C reactive protein in completers and withdrawals (GSTM and MTX). Response to treatment shown as percentage of baseline.

the average values of the three cohorts assimilated reaching $35 \%$ for SJC and 32\%-50\% for TJC at month 72 (table 3, fig 2).

ESR and CRP were reduced to on average $50 \%$ in completers and GSTM withdrawals already after 12 months. The decline of the ESR in the MTX withdrawals was significantly smaller reaching an value of only $91 \%$ of baseline after 12 months. In addition the CRP concentrations increased to $148 \%$ of baseline after 12 months. At month 36, after treatment had been changed, MTX withdrawals showed the same improvement as completers (table 3, fig 3).

The increase in the Ratingen score per month from the beginning of joint symptoms to the start of treatment was calculated to be
0.53 in the group of completers, 0.41 in GSTM withdrawals and 0.29 in MTX withdrawals. During treatment the slope of radiographic progression in the group of completers decreased to $0.30 /$ month between month 12 and 24 with further decrease thereafter. In the group of GSTM withdrawals the progression rate decreased from 0.41 during the first six months of treatment to 0.17 during the second year of treatment, remaining low up to month 48 and gradually increasing thereafter. In contrast, MTX withdrawals showed an increase in radiographic progression from 0.69 during the first half year to 0.86 during the second half year and decreasing after the start of gold or combination treatment. Between month 48 and 60 the progression rate was the same in

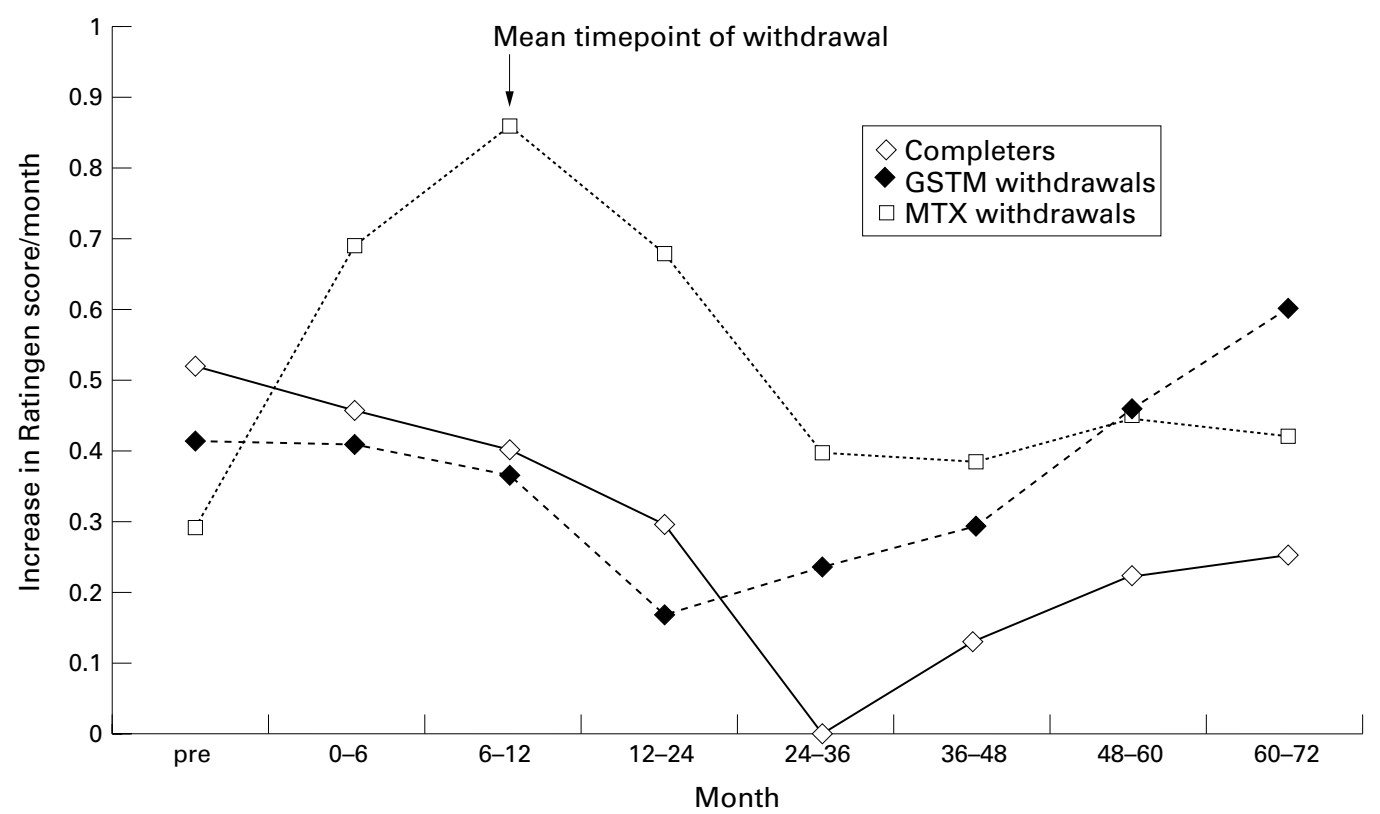

Figure 4 Slope of radiological deterioration in completers and withdrawals (GSTM and MTX). Average increase in Ratingen score per month. 
Table 4 Radiological progression (increase in Ratingen score per month, mean values, (standard deviation))

\begin{tabular}{|c|c|c|c|c|c|c|c|c|}
\hline Month & pre & $0-6$ & $6-12$ & $12-24$ & $24-36$ & $36-48$ & $48-60$ & $60-72$ \\
\hline Completers & $0.52(0.46)$ & $0.46(0.49)$ & $0.40(0.5)$ & $0.30(0.78)$ & $0.00(0.81)$ & $0.14(0.20)$ & $0.23(0.52)$ & $0.26(0.42)$ \\
\hline GSTM withdrawals & $0.41(0.48)$ & $0.41(0.52)$ & $0.37(0.59)$ & $0.17 \dagger(0.35)$ & $0.24(0.36)$ & $0.30(0.60)$ & $0.47(0.61)$ & $0.61^{\star}(0.86)$ \\
\hline MTX withdrawals & $0.29^{\star}(0.45)$ & $0.69(0.99)$ & $0.86^{\star}(1.03)$ & $0.68+(0.85)$ & $0.40(0.33)$ & $0.39^{\star}(0.35)$ & $0.46(0.46)$ & $0.43(0.60)$ \\
\hline
\end{tabular}

(No progression, score increase $=0$; slight progression, score increase $<0.3 /$ month; marked progression, score increase $\geqslant 0.3 /$ month, ${ }^{\star}$ significant difference compared with completers, †significant difference between GSTM and MTX withdrawals, $t$ test, $\mathrm{p}<0.05)$.

both cohorts withdrawn from randomised treatment while patients continuing treatment still had a low progression rate (table 4 , fig 4 ).

In the GSTM withdrawal cohort 14 of 38 patients $(37 \%)$ showed no radiographic progression from the beginning of treatment, compared with 21 of $67(31 \%)$ in the group of completers and 6 of $23(26 \%)$ in the group of MTX withdrawals.

\section{Discussion}

Parenteral gold salts ${ }^{29-38}$ and MTX $^{6-11} 3940$ modify the course of rheumatoid arthritis when given in sufficient doses over a longer period of time. Although the mode of action may be different both drugs extend a similar efficacy in patients with early erosive rheumatoid arthritis. $^{2-4}{ }^{15}$ In several trials and meta-analyses drug survival for MTX has been shown to be significantly longer than that for gold treatment because of a higher toxicity related withdrawal rate in gold treated patients ${ }^{314}$ with more than $50 \%$ of patients dropping out within 36 months. Withdrawals are often described as treatment failures, their outcome is usually not reported in the publication of clinical trials, and these patients are not followed up prospectively for a longer period of time. The only prospective trial performed by the Empire Rheumatism Council ${ }^{42}{ }^{43}$ failed to demonstrate an additional beneficial effect in patients suffering from gold induced toxicity.

This is the first prospective six year follow up of patients withdrawn from a randomised DMARD trial.

Our data are based on a follow up rate of $88 \%$ after 72 months and therefore represent the vast majority of patients recruited for a DMARD trial in early erosive rheumatoid arthritis. Patients withdrawn from the randomised treatment were treated in a standardised fashion and followed up the same way as patients continuing treatment.

Relevant and significant differences could be demonstrated in the clinical and radiological course of patients withdrawn from GSTM and MTX treatment.

MTX improves the course of rheumatoid arthritis only when the treatment is continued in a sufficient dose. MTX treated patients who were later withdrawn showed only a transient improvement after the start of MTX treatment lasting a mean of three months and worsened thereafter. These patients showed a sustained improvement only after starting GSTM as monotherapy or in combination with MTX.

A worsening (relapse) after discontinuation of MTX is a common clinical experience and has been confirmed in numerous trials. ${ }^{1144}$ Even the four week discontinuation of "insufficient" MTX treatment before starting treat- ment with novel drugs resulted in a flare up in the majority of patients. ${ }^{45} \mathrm{~A}$ trial on elective drug discontinuation in patients being in remission showed a significant deterioration in patients receiving placebo when compared with patients continuing their DMARD treatment. $^{46}$

In our study, patients withdrawn from gold treatment demonstrated an improvement of $40 \%$ to $70 \%$ in all clinical parameters similar to patients who continued their randomised treatment. (The good clinical condition of the patients at the time of their discontinuation may reflect the tendency of patients doing well to discontinue treatment for minor side effects.) This improvement was sustained for an average of 24 months after discontinuation of the drug even in patients without further DMARD treatment. Twenty four months is also the duration of gold induced remissions reported by others. ${ }^{23} 47$

Completers and withdrawals had a comparable disease activity at baseline and after six years. The reversibility of the improvement in the GSTM withdrawals and the transient deterioration in MTX treated patients after withdrawal, improving again after introduction of gold treatment, indicates a treatment effect and cannot be explained by a selection of patients with milder or more severe disease.

As the beneficial effect in GSTM withdrawals seems to be limited in duration in many patients, a remission keeping strategy seems to be necessary. After a temporary discontinuation of treatment a further course of gold could be started as soon as the side effects have disappeared ${ }^{48}$ or treatment could be continued with a very low dose despite the existence of side effects. ${ }^{49}$ Ten Wolde et al described a better 12 month outcome in patients continuing DMARD treatment in remission compared with patients stopping and reintroducing after a flare up ${ }^{50}$ confirming the preference for continued treatment.

The clinical observation of a marked improvement or even longlasting remission in patients with gold related toxicity has been confirmed by this prospective six year trial.

In addition, our data support the need for a modification of trial designs: as withdrawals represent the majority of patients in long term drug trials they should not be excluded from efficacy analysis. (Clinically relevant differences between MTX and GSTM treatment are more likely to be detected in withdrawals than in completers). Patients stopping treatment because of relatively mild side effects, being in remission or marked improvement should not be regarded as treatment failures. 
We thank Ms Gudrun Krüger for her secreterial work. Funding: the trial was sponsored in part by a research gran from Lederle Laboratories.

1 Morrasut T, Goldstein R, Cyr M, Karsh J, McKendry RJR. Goldsodiumthiomalat compared to low-dose methotrexate in the treatment of rheumatoid arthritis - a randomised double-blind 26-week trial. J Rheumatol 1989;16:302-6.

2 Rau R, Herborn G, Menninger H, Blechschmidt J Comparison of intramuscular methotrexate and gold sodium thiomalate in the treatment of early erosive allel study of 174 patients. Br J Rheumatol 1997;36:34552.

3 Menninger H, Herborn G, Blechschmidt J, Sander O, Rau R. A 36-month comparative trial of methotrexate and goldsodiumthiomalate in the treatment of early active and erosodiumthiomalate in the treatment of early active and ero-
sive rheumatoid arthritis. Br J Rheumatol 1998;37:1060-8.

4 Rau R, Herborn G, Menninger H, Sangha O. Radiographic progression in early erosive rheumatoid arthritis: 12 month results from a randomised controlled trial comparing methotrexate and gold sodium thiomalate. Br J Rheumatol 1998;37:1220-6

Suarez-Almazor ME, Fitzgerald A, Grace M, Russell AS. A randomised controlled trial of parenteral methotrexate compared with sodium aurothiomalate. J Rheumatol 1988 15:753-6.

6 Kremer JM, Phelps CT. Longterm prospective study of the use of methotrexate in the treatment of rheumatoid arthritis. Arthritis Rheum 1992;35:138-45.

7 Weinblatt ME, Weissman BN, Holdsworth DE, Fraser PA, Maier AL, Falchuk KR, et al. Longterm prospective study of methotrexate in the treatment of rheumatoid arthritis. 84-month update. Arthritis Rheum 1992;35:129-37.

8 Weinblatt ME, Kaplan H, Germain BF. Methotrexate in rheumatoid arthritis: effects on disease activity in rheumatoid arthritis: effects on disease activity in a

9 Sany J, Anaya JM, Lussiez V, Couret M, Combe B, Davres JP, et al. Treatment of rheumatoid arthritis with methotrexate: a prospective open longterm study of 191 cases. J Rheumatol 1991;18:1323-7.

10 Hanrahan PS, Scrivens GA, Russell AS. Prospective long term follow-up of methotrexate therapy in rheumatoid arthritis: toxicity, efficacy and radiological progression. $\mathrm{Br}$ Rheumatol 1989;28:147-53.

11 Rau R, Schleusser B, Herborn G, Karger T. Longterm treatment of destructive rheumatoid arthritis with methotrexate. J Rheumatol 1997;24:1881-9.

12 Wolfe F, Hawley DJ, Cathey MA. Termination of slow acting antirheumatic therapy in RA: A 14 year prospective ing antirheumatic therapy in RA: A 14 year prospective
evaluation of 1017 consecutive starts. J Rheumatol evaluation of 1017

13 Pincus T, Brooks RH, Kim YW, Adams RF, Barber J, Barth $\mathrm{WF}$, et al. Methotrexate is continued over five years significantly longer than other second-line drugs in 536 private practice rheumatoid arthritis patients. Arthritis Rheum 1990;33:40.

14 Felson DT, Anderson JJ, Meenan RF. The comparative efficacy and toxicity of second-line drugs in rheumatoid arthritis. Arthritis Rheum 1990;33:1449-60.

15 Hernández-García C, Jover JA, Morado IC, Bañares A Fernández-Gutiérrez B, Macarrón P, et al. Gold salts and methotrexate in daily practice. Short-term safety and efficacy in rheumatoid arthritis. [Abstract]. Arthritis Rheum 1997;40:S51.

16 Keyszer G, Keysser C, Kruse R, Keysser M. The long-term efficacy and safety of disease modifying antirheumatic efficacy and safety of disease modifying antirheumatic
drugs (DMARD). Results of a meta-analysis of 1681 drugs (DMARD). Results of a meta-analysis of 1681 patients with rheumatoid
tis Rheum 1996;39:S106.

17 van Gestel A, Koopman R, Wijnands M, van de Putte L, van Riel P. Mucocutaneous reactions to gold: a prospective study of 74 patients with rheumatoid arthritis. J Rheumato 1994;21:1814-19.

18 Srinivasan R, Miller BL, Paulus HE: Long term chrysiotherapy in rheumatoid arthritis. Arthritis Rheum 1979; 22:105-10.

19 Lockie LM, Smith DM. Forty seven years experience with gold therapy in 1019 rheumatoid arthritis patients. Semin Arthritis Rheum 1985; 13:238-46.

20 Suarez-Almazor ME, Soskolne CL, Saunders LD, Russell AS. Use of second line drugs for the treatment of rheumatoid arthritis in Edmonton, Alberta. Patterns of prescription and longterm effectiveness. J Rheumatol 1995;22: tion and

21 De La Mata J, Blanco FJ, Gomez Reino JJ. Survival analysis of disease modifying antirheumatic drugs in Spanish rheumatoid arthritis patients. Ann Rheum Dis 1995;54:881-5.

22 Svensson A, Theander J. Skin rashes and stomatitis due to parenteral treatment of rheumatoid arthritis with sodium aurothiomalate. Ann Rheum Dis 1992;51:326-9.

23 Caspi D, Tishler M, Yaron M. Association between gold induced skin rash and remission in patients with rheumatoid arthritis. Ann Rheum Dis 1989;48:730-2.
24 Ropes MW, Bennett GA, Cobb S, Jacox R, Jessar RA. Revision of diagnostic criteria for rheumatoid arthritis. Bull Rheum Dis 1958;9:175-6.

25 Larsen A, Dale K, Eek M. Radiographic evaluation of rheumatoid arthritis and related conditions by standard reference films. Acta Radiol Diagn 1977;18:481-91.

26 WHO handbook for reporting results of cancer treatment. Geneva: World Health Organization, 1979.

27 van Gestel AM, Prevoo MLL, van't Hof MA, van Rijswijk MH, van de Putte LBA, van Riel PCLM. Development and validation of the European League Against Rheumatism Response Criteria for rheumatoid arthritis. Arthritis Rheum 1996;39:34-40.

28 Rau R, Wassenberg S, Herborn G, Stucki G, Gebler A. A new method of scoring radiographic change in rheumatoid arthritis. J Rheumatol 1998;25:2094-107.

29 Larsen A, Horton J, Howland C. The effects of auranofin and parenteral gold in the treatment of rheumatoid arthritis: An x-ray analysis. Clin Rheumatol 1984;3 (suppl 1):97-104.

30 Cats A. Multicentre controlled trial of the effects of different dosage of gold therapy, followed by maintenance dosage. Agents Actions 1976;6:355-63.

31 Luukkainen R, Kajander A, Isomäki H. Effect of gold on progression of erosions in rheumatoid arthritis. Better results with early treatment. Scand J Rheumatol 1977;6: 189-92.

32 Sigler JW, Bluhm GB, Duncan H, Sharp JT, Ensign DC, McCrum WR. Gold salts in the treatment of rheumatoid arthritis. A double blind study. Ann Intern Med 1974;80 21-6.

33 Cooperating Clinics Committee of the American Rheumatism Association. A controlled trial of gold salt therapy in rheumatoid arthritis. Arthritis Rheum 1973;16:353-8.

34 Buckland-Wright JC, Clarke GS, Walker SR. Erosion number and area progression in the wrists and hands of rheumatoid arthritis patients: a quantitative microfocal radiographic study. Ann Rheum Dis 1989;48:25-9.

35 Buckland-Wright JC. Quantitative microfocal radiography detects changes in erosion area in patients with early erosive rheumatoid arthritis treated with myocrisine. J Rheumatol 1993;20:243-7.

36 Sharp JT, Lidsky MD, Duffy J. Clinical responses during gold therapy for rheumatoid arthritis. Arthritis Rheum 1982;25:540-9.

37 Munro R, Madhok R, Thomson EA, Capell HA. The degree of functional improvement over 5 years of IM gold depends on initial disease duration. [Abstract]. Arthritis Rheum 1997;40:S52

38 Roger L, Masi AT, Luther M. High clinical remission rates following early therapy of active rheumatoid arthritis (RA) with aurothioglucose and low-dose triamcinolone. [Abstract]. Arthritis Rheum 1997;40:S51.

39 Drosos AA, Karantanas AH, Psychos D, Tsampoulas C, Moutsopoulos HM. Can treatment with methotrexate influence the radiologic progression of rheumatoid arthriinfluence the radiologic progression

40 Reykdal S, Steinsson K, Sigurjsson K, Brekkan A. Methotrexate treatment of rheumatoid arthritis: effects on radiological progression. Scand J Rheumatol 1989;18: $221-6$

41 Maetzel A, Bombardier C, Strand V, Tugwell P, Wells G. A meta-analysis of treatment termination rates on parenteral gold and methotrexate in rheumatoid arthritis. [Abstract]. Arthritis Rheum 1997;40:S313.

42 The Research Sub-Committee of the Empire Rheumatism Council: Gold therapy in rheumatoid arthritis. Report of a multi-centre controlled trial. Ann Rheum Dis 1960;19:95multi-ce.

43 Report of the Research Sub-Committee of the Empire Rheumatism Council: Relations of toxic reactions in gold Rheumatism Council: Relations of toxic reactions in gold therapy to improvement in
Rheum Dis $1961 ; 20: 335-40$.

44 Hoffmeister RT. Methotrexate therapy in rheumatoid arthritis: 15 years experience. Am J Med 1983;75:69-73.

45 Sander O, Herborn G, Rau R. Flare after discontinuation of "ineffective" disease modifying anti rheumatic drug threatment in active rheumatoid arthritis. [Abstract]. Rheumatology in Europe 1995;24 (suppl 3):226.

46 ten Wolde S, Breedveld FC, Hermans J, Vandenbroucke JP, van de Laar MA, Markusse HM, et al. Randomised placebo-controlled study of stopping second-line drugs in rheumatoid arthritis. Lancet 1996;347:347-52.

47 Adams CH, Cecil RL. Gold therapy in early rheumatoid arthritis. Ann Intern Med 1950;33:163-73.

48 Klinkhoff A, Teufel A. The second course of gold. J Rheumatol 1995;22:1655-6.

49 Klinkhoff A, Teufel A. How low can you go? Use of very low dosage of gold in patients with mucocutaneous reactions. $J$ Rheumatol 1995;22:1657-9.

50 ten Wolde S, Hermans J, Breedveld FC, Dijkmans BA Effect of resumption of second line drugs in patients with rheumatoid arthritis that flared up after treatment discontinuation. Ann Rheum Dis 1997;56:235-9. 